PAPER

\title{
Long term survival after primary intracerebral haemorrhage: a retrospective population based study
}

\author{
R Fogelholm, K Murros, A Rissanen, S Avikainen
}

J Neurol Neurosurg Psychiatry 2005;76:1534-1538. doi: 10.1136/jnnp.2004.055145

See end of article for authors' affiliations

......................

Correspondence to: Dr Rainer Fogelholm, Pappilantie 10 B 8, 02400

Kirkkonummi, Finland; r.fogel@kolumbus.fi

Received

29 September 2004

In revised form

13 February 2005

Accepted

15 February 2005

\begin{abstract}
Objectives: To determine the long term survival and predictors of death in patients with primary intracerebral haemorrhage $(\mathrm{ICH})$ in Central Finland.

Methods: Data were collected retrospectively on all adult patients with first ever ICH in Central Finland county between September 1985 and December 1991. The survival of all patients at the end of December 2002 was investigated. Kaplan-Meier survival curves were constructed and factors associated with both early ( $\leqslant 28$ days) and late deaths determined. Long term survival was compared with the general Finnish population of the same age and sex distribution. The causes of death were compared with those of the population of Central Finland.

Results: 411 patients with first ever ICH were identified, 199 men (mean age 64.9 years) and 212 women (mean age 69.5); 30 died before hospital admission, and 208 (50.6\%) within the first 28 days. In KaplanMeier analysis, at 16 years the cumulative survival was $3.2 \%$ for men and $9.8 \%$ for women. The 28 day survivors had a 4.5 -fold increased annual risk of dying during the first year after $\mathrm{ICH}$, and 2.2-fold during years 2 to 6 . On admission, significant independent predictors of death within the first four weeks were unconsciousness, lateral shift of cerebral midline structures, mean arterial pressure $\geqslant 134 \mathrm{~mm} \mathrm{Hg}$, hyperglycaemia, anticoagulant treatment, and ventricular extrasystoles. Predictors of late death for the 28 day survivors were old age, male sex, and heart failure.

Conclusions: Primary intracerebral haemorrhage has a poor short and long term outcome. The results emphasise the importance of primary and secondary prevention for $\mathrm{ICH}$.
\end{abstract}

$\mathrm{T}$ he short term survival of primary intracerebral haemorrhage (ICH) has been documented in several reports. During the first month after ICH onset the proportion dying has varied from $22 \%$ to $62 \%{ }^{12}$ Studies on long term survival are few: in six the follow up has been for five years or longer, ${ }^{2-7}$ and in only three studies has the follow up been for 10 years or more. ${ }^{257}$

The present analysis of epidemiologically representative ICH patient material was made in order to improve our knowledge of the long term survival and its determinants. We also compared the survival with the age and sex matched general population, and the distribution of the causes of death with that of the basic population from which the patients emerged.

\section{METHODS}

We collected data retrospectively on all adult patients who suffered from ICH between September 1985 and December 1991 in a population of 249500 (1988) living in the catchment area of the Central Hospital of Central Finland (the county of Central Finland). The patients were traced from the discharge lists of the two hospitals and 18 health centres in the area, from death certificates, and from the medical and medicolegal necropsy reports. A prerequisite for accepting ICH as the cause of stroke was confirmation by cranial computed tomography (CT) or necropsy. Secondary ICHs caused by trauma, arteriovenous malformations, or rupture of arterial aneurysms were excluded. In all, 411 patients with first ever ICH were traced, 381 of whom were admitted to the Central Hospital.

The vital status of all patients was checked at the end of December 2002. All medical records held by the Central Hospital, Jokilaakso Hospital, and the health centres were reviewed for recurrent strokes and survival. If necessary, the death certificates were retrieved. The causes of death were classified in five broad groups:

- Vascular diseases included deaths from first ICH, recurrent ICH, new ischaemic or non-specified stroke, coronary heart disease and other cardiac causes, pulmonary embolism, and other vascular causes;

- pneumonia, whether or not associated with first or recurrent ICH;

- malignant diseases;

- traumatic causes;

- miscellaneous diseases.

The information about earlier diseases and current anticoagulant use obtained from the patients or relatives was confirmed by reviewing the previous medical records. Diabetes was recorded in patients on insulin, oral hypoglycaemic drugs, or on dietary restriction, and hypertension if antihypertensive drug treatment was being prescribed. Smoking habits were categorised as never or ever smokers.

Blood pressure was measured on admission, in 94\% within 48 hours after stroke onset. Mean arterial pressure (MAP) was calculated by adding one third of the pulse pressure (systolic minus diastolic blood pressure) to the diastolic pressure. The level of admission consciousness was graded as 1, conscious (alert, somnolent, disoriented); and 2, unconscious/comatose (depending on the response to painful stimuli).

Blood glucose was measured in 345 patients (91\% within 48 hours after stroke onset), and 343 had cranial CT (87\% within 48 hours after stroke onset). All CT films were

Abbreviations: $\mathrm{ICH}$, intracerebral haemorrhage; MAP, mean arterial blood pressure 


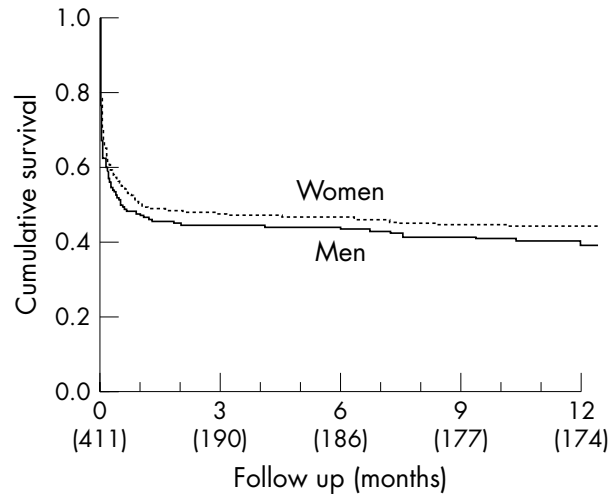

Figure 1 Kaplan-Meier curves showing the probability of 12 month survival, by sex. Numbers of patients in brackets.

available for analysis, which included measurement of haematoma volume $(\mathrm{ml})$ and lateral shift $(\mathrm{mm})$ of cerebral midline structures, evaluation of intraventricular or subarachnoid spread, and hydrocephalus. Haematoma volume was measured using a planimetric computer program. ${ }^{8}$

\section{Statistical methods}

We used $\chi^{2}$ testing to search for variables that were individually associated $(\mathrm{p}<0.1)$ with the short term $(\leqslant 28$ days) and long term ( $>28$ days) survival. Twenty six variables were included: age (tertiles), sex, presence of hypertension, coronary heart disease including myocardial infarction, heart failure, diabetes, anticoagulant treatment, smoking habits (never/ever smokers), consciousness (conscious/unconscious), MAP and blood glucose (both dichotomised at median), haematoma volume (quartiles), midline shift (tertiles), presence of intraventricular or subarachnoid spread, and hydrocephalus. The following ECG items were included: left ventricular hypertrophy, pathological Q wave, atrial fibrillation, left bundle branch block, tachycardia (heart rate $>100$ beats/min), bradycardia (heart rate $<60$ beats/ min), ST segment elevation $>2.5 \mathrm{~mm}$, ST segment depression $>1.0 \mathrm{~mm}$, ventricular extrasystoles, and a negative $\mathrm{T}$ wave.
Hemiparesis was not included in the variables because a reliable evaluation in unconscious patients is usually impossible. The large number of patients who died soon after admission before any examinations were done explains the missing data on, for example, cranial CT.

The Kaplan-Meier technique was used to generate survival curves for men and women, and the age tertiles. Logistic regression and Cox proportional hazards regression analyses were undertaken on patients admitted to hospital to identify significant independent predictors of short and long term survival. The analyses were carried out both with and without mean substitution of missing data. Individual variables that were associated $(\mathrm{p}<0.1)$ with survival were included in the analyses. All CT variables were highly intercorrelated and we chose-because of easy accessibility-lateral shift of the midline structures to represent the CT findings. Forward Wald stepwise selection with entry 0.05 and removal 0.1 was used. All statistical calculations were done using SPSS software (version 10.0).

The expected survival of the age and sex matched general population was calculated from Finnish Life Tables 1998. The causes of death were compared with the average annual numbers of deaths during a five year period (1994 to 1998) in the population of Central Finland (http://statfin.stat.fi/ stat.web/).

The study protocol was approved by the Finnish Ministry of Social Affairs and Health, which authorised the perusal of all case reports of ICH patients who lived in the Central Hospital District.

\section{RESULTS}

Between September 1985 and December 1991 we identified 411 first ever ICH patients in the study population (incidence 26/100 000/year): 199 men (mean (SD) age, 64.9 (11.5) years), and 212 women (69.5 (11.1) years). Eighty four per cent of the haematomas were supratentorial and $16 \%$ infratentorial. Thirty patients died before admission, and 381 were admitted to the emergency room of the Central Hospital, 91\% within 24 hours of ICH onset. There were 359 patients who were treated conservatively, and 26 who had surgical evacuation of the haematoma. The median follow up for individual patients was 26 days (range 0 to 6191 days).

The early case fatality was very high; 91 patients $(22 \%)$ died within 24 hours of onset, 173 (42\%) were dead on day 7 ,

\begin{tabular}{|c|c|c|c|c|}
\hline Variable & $\mathrm{n}$ & Odds ratio & $95 \% \mathrm{Cl}$ & p Value \\
\hline \multicolumn{5}{|l|}{ Consciousness } \\
\hline Conscious/somnolent/disoriented & 228 & 1.0 & - & - \\
\hline Unconscious/comatose & 84 & 15.3 & 6.6 to 35.4 & 0.000 \\
\hline \multicolumn{5}{|l|}{ Shift of midline structures (tertiles) } \\
\hline $0 \mathrm{~mm}$ & 100 & 1.0 & - & - \\
\hline $1-5 \mathrm{~mm}$ & 112 & 2.7 & 1.2 to 6.2 & 0.019 \\
\hline 6-24 mm & 100 & 13.5 & 5.6 to 32.5 & 0.000 \\
\hline \multicolumn{5}{|l|}{ Admission mean arterial pressure } \\
\hline$<134 \mathrm{~mm} \mathrm{Hg}$ & 162 & 1.0 & - & - \\
\hline$\geqslant 134 \mathrm{~mm} \mathrm{Hg}$ & 150 & 2.7 & 1.4 to 5.2 & 0.003 \\
\hline \multicolumn{5}{|l|}{ Admission blood glucose } \\
\hline$<7.7 \mathrm{mmol} / \mathrm{l}$ & 160 & 1.0 & - & - \\
\hline$\geqslant 7.7 \mathrm{mmol} / \mathrm{l}$ & 152 & 2.6 & 1.4 to 4.9 & 0.004 \\
\hline \multicolumn{5}{|l|}{ Anticoagulant treatment } \\
\hline No & 272 & 1.0 & - & - \\
\hline Yes & 40 & 2.8 & 1.2 to 6.8 & 0.021 \\
\hline \multicolumn{5}{|l|}{ Ventricular extrasystoles } \\
\hline No & 286 & 1.0 & - & - \\
\hline Yes & 26 & 3.2 & 1.1 to 9.6 & 0.035 \\
\hline Constant & & & 0.027 & 0.000 \\
\hline
\end{tabular}


Table 2 Significant independent predictors of late death in the 28 day survivors

\begin{tabular}{lclll}
\hline Variable & $\mathbf{n}$ & Relative risk & $\mathbf{9 5 \%} \mathbf{C l}$ & $\mathbf{p ~ V a l u e ~}$ \\
\hline Age tertiles & 79 & 1.0 & - & - \\
$\quad<65$ years & 63 & 1.9 & 1.3 to 2.9 & 0.001 \\
$\quad 65-73$ years & 60 & 3.2 & 2.1 to 4.8 & 0.000 \\
$>73$ years & & & & \\
Sex & 107 & 1.0 & 1.0 to 2.0 & 0.027 \\
$\quad$ Women & 95 & 1.4 & & \\
$\quad$ Men & & & - & - \\
Heart failure & 163 & 1.0 & 1.3 to 2.8 & 0.001 \\
$\quad$ No & 39 & 1.9 & & \\
$\quad$ Yes & & &
\end{tabular}

and by four weeks after onset 208 had died $(51 \%$, 95\% confidence interval (CI), $46 \%$ to $55 \%$ ). At one year, $58 \%$ had died (95\% CI, $53 \%$ to $62 \%$; fig 1), and at five years, $73 \%(69 \%$ to $78 \%$ ). At 16 years after the ICH the cumulative KaplanMeier survival was $6.3 \%$ for men, and $9.8 \%$ for women. The causes of death of the 208 patients who died during the first 28 days were: the index ICH (200), pulmonary embolism (4), myocardial infarction (3), and mesenteric artery thrombosis (1).

\section{Twenty eight day survival}

Sixty one (16\%) of the 381 patients who were admitted died on the day of admission. In single explanatory variable analysis, 13 variables were associated with death during the first four weeks: unconsciousness, haematoma volume, midline shift, intraventricular and subarachnoid spread, hydrocephalus, anticoagulant treatment, atrial fibrillation, tachycardia (heart rate $>100$ beats/min), ventricular extrasystoles, negative $\mathrm{T}$ wave, blood glucose $>7.3 \mathrm{mmol} / \mathrm{l}$, and MAP $>134 \mathrm{~mm} \mathrm{Hg}$. Logistic regression analysis of 312 patients with complete data revealed six significant independent predictors of death during the first four weeks (table 1). Unconsciousness and lateral shift of cerebral midline structures $\geqslant 6 \mathrm{~mm}$ were the most important predictors. The odds ratios of MAP $\geqslant 134 \mathrm{~mm} \mathrm{Hg}$, blood glucose $\geqslant 7.7 \mathrm{mmol} /$ $\mathrm{l}$, anticoagulant treatment at the time of ICH onset, and ventricular extrasystoles in the ECG varied from 3.2 to 2.6. Analysis of all 381 admitted patients with mean substitution of missing data gave a similar result.

Owing to missing clinical evaluation, the 30 patients who died before admission were not included in the analysis. The

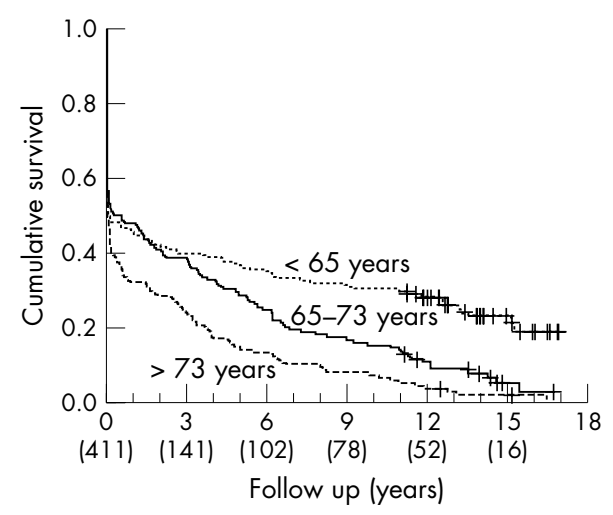

Figure 2 Kaplan-Meier curves showing the probability of long term survival, by age tertiles. Numbers of patients in brackets. + = censored cases. mean age and prevalence of previous diseases were similar to the 381 admitted patients, but the proportion of men was higher $(\mathrm{p}=0.012)$.

\section{Long term survival}

Long term survival was analysed on the basis of the 203 patients who were alive after the first 28 days. Single explanatory variables associated with long term survival were old age, male sex, coronary heart disease, heart failure, and atrial fibrillation. In Cox regression analysis, only three variables appeared as significant independent predictors of death during long term follow up. Age over 73 years was the most important, followed by heart failure and male sex (table 2).

Figure 2 shows the Kaplan-Meier survival curves for age tertiles. Patients less than 65 years of age had the best prognosis, with $19.3 \%$ surviving for 16 years after ICH; of the two groups of older patients only $2.7 \%$ and $1.8 \%$ were alive. Compared with the general Finnish population of the same age and sex, the annual risk of dying during the first year was increased 4.5-fold and during years 2 to 6, 2.2-fold; after this the risk declined and was 0.9 -fold during years 7 to 16 . The patients who died during the first six years were significantly older and had a higher prevalence of hypertension, heart failure, atrial fibrillation, and hydrocephalus than the six year survivors.

As stated above, 200 of 208 deaths within 28 days after onset were from the index ICH. The causes of death of the 159 patients dying after day 28 were quite different, and only $34 \%$ were from cerebrovascular disease. However, the distribution of causes of death of the 28 day survivors differed from that of the general population of Central Finland (table 3). The odds ratios of death from cerebrovascular diseases and pneumonia were 4.0 and 3.9, respectively, but only 0.5 for coronary heart and 0.4 for malignant diseases.

\section{Recurrent strokes}

Seventy one $(35 \%)$ of the 28 day survivors had recurrent strokes during the follow up. Twenty three patients had verified ICH, two of them twice, and one three times. The first recurrence occurred at a median of 30 months (range 2 to 158) after the index ICH, and $50 \%$ of the recurrences were fatal. Twenty one patients suffered from ischaemic stroke at a median of 74 months (range 4 to 168) after ICH, and 27 from an undefined stroke at median 55 months (range 1 to 174) after ICH. Of the ischaemic and undefined strokes, 27 were fatal.

\section{DISCUSSION}

The acute case fatality rate of ICH was very high. Every fifth patient died on the day of ICH onset, and $51 \%$ were dead by 
Table 3 Causes of death during the long term follow up of the patients with intracerebral haemorrhage who survived the first 28 days

\begin{tabular}{|c|c|c|c|}
\hline Cause of death & $\begin{array}{l}\text { ICH patient } \\
\text { deaths (\%) }\end{array}$ & $\begin{array}{l}\text { Population } \\
\text { deaths (\%) }\end{array}$ & $\begin{array}{l}\text { Odds ratio } \\
(95 \% \mathrm{CI})\end{array}$ \\
\hline Cerebrovascular diseases & $54(34.0)$ & $285(11.4)$ & $4.0(2.8$ to 5.7$)$ \\
\hline First intracerebral haemorrhage & 14 & NA & \\
\hline Recurrent intracerebral haemorrhage & 13 & NA & \\
\hline Acute stroke (infarct/non-defined) & 27 & NA & \\
\hline Cardiovascular diseases & $38(23.9)$ & $888(35.6)$ & $0.6(0.4$ to 0.8$)$ \\
\hline Coronary heart disease/MI & $25(15.7)$ & $700(28.1)$ & $0.5(0.3$ to 0.7$)$ \\
\hline Other cardiac disease & $7(4.4)$ & $91(3.6)$ & $1.2(0.6$ to 2.7$)$ \\
\hline Other vascular diseases & $6(3.8)$ & $97(3.9)$ & $1.0(0.4$ to 2.2$)$ \\
\hline Pneumonia & $29(18.2)$ & $135(5.4)$ & $3.9(2.5$ to 6.0$)$ \\
\hline Malignant diseases & $14(8.8)$ & $501(20.0)$ & $0.4(0.2$ to 0.7$)$ \\
\hline Trauma & $3(1.9)$ & $125(5.0)$ & $0.4(0.1$ to 1.2$)$ \\
\hline Miscellaneous & $16(9.9)$ & $500(20.0)$ & \\
\hline Unknown & $5(3.1)$ & $60(2.4)$ & \\
\hline Total & 159 & 2494 & \\
\hline
\end{tabular}

28 days. The most important independent predictors of death within the first 28 days were unconsciousness on admission and $\geqslant 6 \mathrm{~mm}$ lateral shift of cerebral midline structures. Other predictors were high admission MAP and blood glucose, current anticoagulant treatment, and ventricular extrasystoles on the ECG.

The predictors of dying during long term follow up of the 28 day survivors were old age, heart failure, and male sex. During the first year after ICH, the risk of dying among the 28 day survivors was increased over fourfold compared with the general Finnish population of the same age and sex. Thereafter the risk diminished, and after six years there was no difference.

The strengths of the study are the large number of epidemiologically representative patients. Because not all stroke patients in the population had CT, or necropsy in the case of death, some ICH patients must have remained undiagnosed. The annual incidence 26/100 000 obtained in the present study is, however, not significantly smaller than the 31/100 000 obtained in an epidemiological study of 158 patients from a restricted area of Central Finland, the Jyväskylä region, from which virtually all acute strokes were admitted to the Central Hospital. ${ }^{8}$ These 158 patients are included in the patient material of this study.

The weaknesses of the study mainly reflect its retrospective nature; not all the patients had complete baseline data, the timing and performance of auxiliary examinations varied, and follow up often depended on reviews of the medical records and death certificates.

The 28 day case fatality of $51 \%$ ( $95 \%$ CI, $46 \%$ to $55 \%$ ) in our study, which includes patients who died before admission, is similar to the mean value in previous population based studies of $50 \%$ (95\% CI, $46 \%$ to $54 \%)^{2}{ }^{9-12}$ but significantly higher than the $39 \%$ ( $37 \%$ to $41 \%$ ) obtained from hospital based studies. ${ }^{156}{ }^{13-20}$ Because there is no effective treatment for ICH, different case mixes probably explain these divergent rates. Age may not be a decisive factor because the mean ages of all these studies has been between 60 and 69 years. Different time lags between ICH onset and admission could, on the other hand, explain the difference fairly well, because late admissions exclude patients dying acutely after ICH onset.

At one year, $58 \%$ of our patients had died-similar to the mean of previous population based studies of 59\% (95\% CI, $54 \%$ to $63 \%)^{2} 3^{12}$ but again significantly higher than the $50 \%$ $(48 \%$ to $53 \%)$ in the hospital based studies. ${ }^{5620}$ At five years, the situation was similar, the present study and previous population based studies ${ }^{2-4}$ being of the same magnitude ( $73 \%$ and $71 \%$ deceased, respectively) but only $61 \%$ (95\% CI, 59\% to $64 \%$ ) were dead in the hospital based studies. ${ }^{56}$ The same trend is obvious in studies with 10 years of follow up. In the Danish study, ${ }^{2}$ (Brönnum-Hansen $\mathrm{H}$, personal communication), $81 \%$ of the patients were dead at 10 years, and $89 \%$ at 15 years. In Perth, extrapolated from the Kaplan-Meyer curve, $75 \%$ were dead at 10 years. ${ }^{7}$ The results of the present study, with $82 \%$ dead at 10 years and $90 \%$ dead at 15 years, are of the same magnitude as the two earlier population based studies. In the only hospital based study from Toronto, the 10 year and 13 year mortalities, extrapolated from the Kaplan-Meier survival curve, were much lower, at $48 \%$ and $54 \%$, respectively. ${ }^{5}$ It is reasonable to assume that the lower mortality from hospital based studies reflects the omission of prehospital deaths.

Independent significant predictors of early death have been identified by multivariate analysis in eight studies. ${ }^{1}{ }^{5} 14$ 15 $17-20$ Old age, disturbed consciousness/low Glasgow coma scale score, haematoma volume, intraventricular and subarachnoid spread, midline shift, narrow pulse pressure, high pulse pressure, infratentorial location, and high blood glucose have been such predictors. In our study, in addition to unconsciousness, midline shift, and high blood glucose, an admission MAP of $\geqslant 134 \mathrm{~mm} \mathrm{Hg}$, anticoagulant treatment, and ventricular extrasystoles emerged as independent predictors.

Old age has been found to be an exclusive predictor of death during a five year follow up of ICH patients who recovered and returned home after a mean of 29 days from onset (Vermeer S, personal communication). ${ }^{6}$ There are no comments about other predictors in the few long term follow up studies. We were able to identify three significant independent predictors of death during the long term follow up of the 28 day survivors: old age, cardiac failure, and male sex.

\section{Conclusions}

ICH is still a serious disease, with every fifth patient dying within 24 hours of onset, 50\% dying by four weeks, and according to Kaplan-Meier analysis, only around 8\% being alive after 16 years. We were able to identify six variables that predicted death within the first 28 days after onset, and three predictors of death during long term follow up. Unfortunately, most of the predictors are not amenable to treatment. In theory, a high admission MAP and blood glucose could be treated, but the possible impact of this on 
the outcome is an open question. In addition, there is no agreement on the value of surgical evacuation of supratentorial haematomas.

Primary and secondary prevention in addition to good care in the acute phase are presently the only means of managing the problem of ICH. The value of long term antihypertensive treatment as primary and secondary prevention is not questioned. The role of active treatment of high blood pressure during the acute phase remains open.

\section{ACKNOWLEDGEMENTS}

We thank Drs Henrik Brönnum-Hansen, Sarah Vermeer, and Michael Hill for providing us with detailed data from their studies.

\section{Authors' affiliations}

R Fogelholm, Department of Neurology, University of Helsinki, Helsinki, Finland

K Murros, Department of Neurology, Jorvi Hospital, Jorvi, Finland A Rissanen, S Avikainen, Department of Neurology, Central Hospital of Central Finland, Finland

Competing interests: none declared

\section{REFERENCES}

1 Cheung RTF, Zou L-Y. Use of original, modified, or new intracerebral hemorrhage score to predict mortality and morbidity after intracerebral hemorrhage. Stroke 2003;34:1717-22.

2 Brönnum-Hansen $H$, Davidsen $M$, Thorvaldsen $P$, for the Danish MONICA Study Group. Long-term survival and causes of death after stroke. Stroke $2001 ; 32: 2131-6$.

3 Dennis MS, Burn JPS, Sandercock PAG, et al. Long-term survival after firstever stroke: the Oxfordshire Community Stroke Project. Stroke 1993;24:796-800.

4 Hankey GJ, Jamrozik K, Broadhurst RJ, et al. Five-year survival after first-ever stroke and related prognostic factors in the Perth Community Stroke Study. Stroke 2000;31:2080-6.
5 Hill MD, Silver FL, Austin PC. Rate of stroke recurrence in patients with primary intracerebral hemorrhage. Stroke 2000;31:123-7.

6 Vermeer SE, Franke CL, Koudstaal PJ, et al. Long-term prognosis after recovery from primary intracerebral hemorrhage. Neurology 2002;59:205-9.

7 Hardie K, Hankey GJ, Jamrozik K, et al. Ten-year survival after first-ever stroke in the Perth Community Stroke Study. Stroke 2003;34:1842-6

8 Fogelholm R, Nuutila M, Vuorela A-L. Primary intracerebral haemorrhage in the Jyväskylä region, Central Finland, 1985-89: incidence, case fatality rate, and functional outcome. J Neurol Neurosurg Psychiatry 1992;55:546-52.

9 Giroud M, Gras P, Cheden N, et al. Cerebral haemorrhage in a French prospective population study. J Neurol Neurosurg Psychiatry 1991;54:595-8.

10 Bamford J, Sandercock P, Dennis M, et al. A prospective study of acute cerebrovascular disease in the community: the Oxfordshire Community Stroke Project-1981-86. 2. Incidence, case fatality rates and overall outcome at one year of cerebral infarction, primary intracerebral and subarachnoid haemorrhage. J Neurol Neurosurg Psychiatry 1990;53:16-22.

11 Hallström B, Norrving B, Lindgren A. Stroke in Lund-Orup, Sweden. Improved long-term survival among elderly stroke patients. Stroke 2002;33:1624-9.

12 Anderson CS, Chakera TMH, Stewart-Wynne EG, et al. Spectrum of primary intracerebral haemorrhage in Perth, Western Australia, 1989-90: incidence and outcome. J Neurol Neurosurg Psychiatry 1994;57:936-40.

13 Fieschi C, Carolei A, Fiorelli $M$, et al. Changing prognosis of primary intracerebral hemorrhage: results of a clinical and computed tomographic follow-up study of 104 patients. Stroke 1988;19:192-5.

14 Daverat P, Castel JP, Dartigues JF, et al. Death and functional outcome after spontaneous intracerebral hemorrhage. A prospective study of 166 cases using multivariate analysis. Stroke 1991;22:1-6.

15 Tuhrim S, Dambrosia JM, Price TR, et al. Prediction of intracerebral hemorrhage survival. Ann Neurol 1988;24:258-63.

16 Hemphill JC, Bonovich DC, Besmertis L, et al. The ICH score. A simple, reliable grading scale for intracerebral hemorrhage. Stroke 2001;32:891-7.

17 Mase G, Zorzon M, Biasutti E, et al. Immediate prognosis of primary intracerebral hemorrhage using an easy model for he prediction of survival. Acta Neurol Scand 1995;91:306-9.

18 Moulin T, Tatu L, Crepin-Leblond T, et al. The Besancon Stroke Registry: an acute stroke registry of 2500 consecutive patients. Eur Neurol 1997;38: 10-20.

19 Franke CL, van Swieten JC, Algra A, et al. Prognostic factors in patients with intracerebral haemorrhage. J Neurol Neurosurg Psychiatry 1992;55:653-7.

20 Portenoy RK, Lipton RB, Berger AR, et al. Intracerebral haemorrhage: a model for the prediction of outcome. J Neurol Neurosurg Psychiatry 1987;50:976-9. 